\title{
Exploração dos recursos naturais e conflitos sociais na Gleba Nova Olinda
}

\section{Exploration of natural resources and social conflits of Gleba Nova Olinda}

Vania Lucia Lemos Catete - Mestrado em Serviço Social, com ênfase em Políticas Públicas e Desenvolvimento na Amazônia pelo Programa de Pós-Graduação em Serviço Social da Universidade Federal do Pará. E-mail: vaniacatete28@gmail.com

Solange Maria Gayoso da Costa - Doutorado em Ciências Socioambientais pelo Núcleo de Altos Estudos Amazônicos, UFPA. Professora da Universidade Federal do Pará e pesquisadora do Instituto Nova Cartografia Social. E-mail: gayososol@yahoo.com.br

\section{Resumo}

$\mathrm{O}$ artigo apresenta reflexões preliminares sobre os conflitos sociais entre madeireiros e indígenas na Gleba Nova Olinda no estado do Pará. Para a coleta das informações utilizou-se o levantamento documental e a realização de entrevistas. Os resultados apontam que a estratégia principal utilizada pelos madeireiros na garantia da posse da terra para a exploração dos recursos naturais são os atos de ameaças e criminalização das lideranças indígenas. Conclui-se que a não resolução do conflito e a judicialização do processo, iniciado em 2006, possibilita que os recursos naturais continuem sendo explorados na região colocando em risco a permanência e sobrevivência dos indígenas.

\begin{abstract}
This paper presents preliminary reflexions about social conflicts between loggers and native groups in Gleba Nova Olinda region, in the state of Para. For collecting of the informations were used documental lifting and accomplished interviews. The results show the main strategy used by loggers for land tenure and to explore natural resources are threats and criminalization of leaderships from these native people. We conclude that a non-solution of these conflicts and the legalization of process, started in 2006, allows that natural resources continue to be explored in this location and endangering permanency and survival of these native groups.
\end{abstract}

\section{Keywords}

Exploration. Conflicts. Gleba Nova Olinda. 


\section{INTRODUÇÃO}

A acumulação de capital na Amazônia brasileira tem se caracterizado pela exacerbação da exploração do trabalho e da natureza. Dentre as formas dessa exploração destacam-se, historicamente, a extração ilegal madeireira, os grandes empreendimentos de infraestrutura e logística, o agronegócio e a mineração que, inseridos na lógica do modelo de desenvolvimento brasileiro, têm provocado intensos processos de (des)territorialização de grupos sociais.

A disputa por território e consequentemente pelo domínio da exploração dos recursos naturais na Amazônia se renova e aprimora na contemporaneidade. Há uma renomeação de prepostos, uma atualização e um aprimoramento de antigas táticas, mas os resultados continuam amplamente desfavoráveis aos excluídos desse processo: pequenos produtores, assentados de reforma agrária, povos e comunidades tradicionais (MESQUITA, 2011).

Tal processo pode ser observado no Oeste do estado do Pará, o qual se caracteriza como uma região de fronteira de expansão da sociedade nacional e do capital, que lhe dita o ritmo de expansão e avança abrindo e pavimentando estradas, projetando um complexo de hidrelétricas no rio Tapajós, instalando grandes projetos de mineração, assim como o agronegócio, que segue pela BR163, do Mato Grosso em direção ao Pará.

O modelo de desenvolvimento econômico aplicado à fronteira amazônica, aqui em particular no oeste do Pará, tem combinado a exploração desenfreada de recursos naturais e a violação de direitos territoriais, que resguardam modos de vida de comunidades tradicionais. Segundo Loureiro (2009, p. 21), as políticas executadas na região, de caráter elitista e patrimonialista, têm induzido maior acumulação de capital por grupos econômicos privados, nacionais, estrangeiros e multinacionais gerando um processo de exclusão de povos, comunidades tradicionais e camadas urbanas que não integram essas elites.

As tensões decorrentes desse tipo de intervenção sobre a Amazônia têm fortalecido a polarização das elites e do Estado em relação a grupos sociais que habitam o interior da região, uma vez que as terras historicamente ocupadas por esses grupos geralmente são alvos de interesses econômicos em virtude da diversidade de riquezas naturais que possuem. A ocupação econômica da fronteira amazônica visando à exploração da matéria-prima tem alijado do processo povos e comunidades tradicionais que, por sua relação com a terranatureza, são consideradas primitivas, atrasadas e que atrapalham o progresso e o desenvolvimento, "cujo modo de viver seria incompatível com a vida moderna [...] esses grupos sociais são barrados, freados em suas pretensões e aspirações 
de manter suas formas de vida, consideradas pela elite e pelo Estado como improdutivas e arcaicas" (LOUREIRO, 2009, p. 21-22).

O caso da Gleba Nova Olinda, localizada nessa região do estado do Pará, é bem emblemático, no sentido de entendermos o processo de ocupação da região visando a exploração dos recursos naturais, em favorecimento de determinado segmento do setor econômico e com anuência do Estado. A referida gleba é área de terras públicas ${ }^{1}$, sob jurisdição do estado do Pará e arrecadadas em nome do Instituto de Terras do Pará (ITERPA).

A Gleba Nova Olinda, que compõe o conjunto de Glebas Estaduais Arapiuns/Mamurú, possui 172.905,413ha e fica entre os rios Aruã e Maró, afluentes do rio Arapiuns, no município de Santarém. É composta por 14 comunidades, sendo 11 comunidades divididas entre ribeirinhos, pescadores e extrativistas e três aldeias indígenas (São José III, Novo Lugar e Cachoeira do Maró), quem vêm se articulando politicamente e socialmente na reivindicação pelo direito ao território, por meio da demarcação da Terra Indígena (TI) Maró, para se firmarem enquanto etnias Borari e Arapium.

A área reivindicada como correspondente à TI Maró tem uma população de 239 habitantes, distribuídas em 43 famílias das etnias Borari e Arapium. Os Borari estão predominantemente localizados na comunidade de Novo Lugar (67 pessoas), enquanto os Arapium se encontram em maioria na Cachoeira do Maró (88 pessoas) e em São José III (84 pessoas) (FUNAI, 2011).

Conforme relatório do IBAMA (2007), a Gleba Nova Olinda apresenta um grande potencial de recursos naturais, principalmente em relação à fauna e à flora, a TI Maró encontra-se cravada nesse mosaico de recursos naturais, que possui alto valor ecológico e financeiro, com destaque para espécies de madeiras bem visadas no mercado, como: massaranduba (Manikara sp.), angelim (Hymenolobium excelsum), jatobá (Hymenaea courbari) e cumaru (Dipterix).

Inseridos num processo de reivindicação pelo uso coletivo do território, os povos da TI Maró desvelaram seu pertencimento ${ }^{2}$ étnico frente ao Estado a

\footnotetext{
"A noção de terras públicas [...] é associada diretamente com o controle da terra por parte do Estado. Nessa concepção, a terra pertence, ao menos formalmente, a todos os cidadãos do país. Porém, é o aparelho de Estado que determina os usos dessas terras, supostamente em benefício da população em seu conjunto. Na realidade, esses usos tendem a beneficiar alguns grupos de cidadãos e, ao mesmo tempo, prejudicar outros. Consequentemente, o usufruto particular das terras públicas se converte numa luta pelo controle do aparelho do Estado ou, no mínimo, pelo direcionamento de suas ações em benefício de um ou outro grupo especifico de cidadãos (LITTLE, 2002 apud RECID, 2011).

2 O procedimento de demarcação da Terra Indígena Maró foi iniciado pela Fundação Nacional do Índio (FUNAI) em 2008, e já vinha sendo requerido pelos indígenas desde 2003. Em 2010, a FUNAI concluiu o Relatório Circunstanciado de Identificação e Delimitação da TI Maró, contudo, não o publicou. Diante da demora, o Ministério Público Federal (MPF) ajuizou ação pedindo mais rapidez no procedimento, devido ao acirramento do conflito entre os povos
} 
partir da década de 2000, quando passaram a ter seu modo de vida alterado e ameaçado por madeireiras.

As reflexões empreendidas neste artigo objetivam apresentar a dinâmica do processo de apropriação, uso e exploração dos recursos naturais na Gleba Nova Olinda e os conflitos decorrentes entre madeireiros, sojicultores e indígenas, destacando as estratégias empregadas por esses agentes sociais.

\section{NATUREZA DO CONFLITO}

Conforme Costa (2012), os conflitos ocorridos na Gleba Nova Olinda envolvem diferentes agentes sociais e retratam uma complexidade de relações sociais e institucionais oriundas do processo de expansão da fronteira agrícola ${ }^{3}$, em que a intervenção e a não intervenção do Estado têm explicitamente contribuído para seu acirramento.

No caso da Gleba Nova Olinda o governo estadual do Pará, por meio de seus organismos reguladores de terra e unidades de conservação, tem atuado ativamente na definição do uso e exploração dos recursos naturais com diferentes dispositivos ${ }^{4}$, dentre os quais destacam as Autorizações de Detenção de Imóvel Público (ADIP) e as denominadas permutas de terras. As ADIP, criadas ainda no primeiro governo de Simão Jatene (2002 a 2006), constituíram os instrumentos legais que facilitaram a exploração madeireira por meio da permissão de regularização fundiária temporária de áreas com grande oferta de recursos madeireiros; nesse período foram emitidas 55 ADIP para diferentes glebas estaduais. Em 2004, foi concedida uma ADIP para a área de abrangência da Gleba Nova Olinda III e em 2006, outras três ADIP para a área de abrangência

indígenas e os agentes econômicos no interior da gleba. Em outubro de 2011, obedecendo à decisão judicial, a FUNAI publicou no Diário Oficial da União o Relatório Circunstanciado de Identificação e Delimitação (RCID), da Terra Indígena Maró.

3 A fronteira agrícola representa uma área mais ou menos definida de expansão das atividades agropecuárias sobre o meio natural [...] Desde os anos 1960, em especial a partir da construção da Rodovia Belém-Brasília, a política que norteou o avanço da fronteira econômica na Amazônia estruturou-se de forma a permitir a integração do mercado nacional e as estruturas produtivas de acumulação do capital. Foi por meio de incentivos fiscais que o Estado procurou atrair capital e empreendedores de diversos setores da economia que se deslocam para o norte do país [...] Os planos recentes do governo têm sido fundamentais para ampliar o desenho da integração do Brasil com os países limítrofes. A orientação observada na política nacional é traçar medidas que reforcem a integração de mercados como os países que se alinham nas amplas fronteiras da região amazônica, sob a liderança pretendida do Brasil (CASTRO, E.; MONTEIRO, M.; CASTRO, C, 2002, p. 06).

4 Adota-se o entendimento sobre o termo "dispositivo" no sentido utilizado por Foucault (1979, p. 244), que considera um conjunto heterogêneo "de discursos, instituições, de organizações arquitetônicas, decisões regulamentares, leis, medidas administrativas, enunciados científicos, proposições filosóficas, morais, filantrópicas". O dispositivo é a "rede que se pode estabelecer entre estes elementos". 
das Glebas Nova Olinda II e quatro para Nova Olinda (COSTA, 2012; ARENZ; FIGUEIREDO; PEIXOTO, 2012).

Além das ADIP, em 2006, por meio do Decreto no․ 2.472/2006, o governo do estado do Pará autorizou assentamento na Gleba Nova Olinda, onde 25 áreas de terras foram destinadas aos permutados. Os denominados permutados são empresários-fazendeiros do Sul do Brasil, que na década de 1980, adquiriram títulos fundiários do governo do estado no âmbito do Projeto Integrado Trairão, desenvolvido pelo Instituto de Terras do Pará (ITERPA) na Gleba Altamira VI, no município de São Félix do Xingu. Tratava-se de terra tradicionalmente ocupada há centenas de anos pelos índios Kayapós, para a qual a FUNAI, por meio do Decreto $\mathrm{n}^{\circ}$ 98.865/1990, determinou que essas terras constituíram-se área imemorial indígena, obrigando a retirada dos ocupantes exógenos. Forçados a sair, os fazendeiros exigiam do governo do estado a indenização dos valores pagos pela aquisição daquelas terras ou a oferta de outra área como compensação. O governo estadual destina então áreas da Gleba Nova Olinda, repetindo o procedimento anteriormente adotado de destinação de áreas tradicionalmente ocupadas para novos habitantes (COSTA, 2012; ARENZ; FIGUEIREDO; PEIXOTO, 2012).

Esses dois instrumentos jurídicos (ADIP e permuta) conduziram para uma acelerada ocupação e exploração da madeira no conjunto das glebas MamurúArapiuns, fato que ocasionou uma série de conflitos socioterritorias na região. A concessão de permuta além de garantir terras de uso da população tradicional da gleba Nova Olinda aos empresários do sul, também atribui-lhes a responsabilidade de realizar a demarcação (autodemarcação) e o georeferenciamento tanto de suas terras, como das terras dos povos que ali já habitavam há dezenas de anos, desobrigando assim, o Estado de sua função de demarcação das terras. Tal processo tem sido acompanhado pelos indígenas, desde o ano de 2002 e se constituiu na motivação para sua organização e luta pela regularização da terra indígena, como pode-se ver no relato de $\mathrm{DB}$, liderança indígena:

foi dia 12 de fevereiro de 2002, na época eu fazia estágio no IBAMA, seis madeireiras entraram com o pedido de pose no IBAMA, porque eles estavam entrando numa área do município de Santarém. Criou-se a reserva do povo Kayapó, no Sul do Pará e esses madeireiro, eles estavam lá, foi feito a demarcação da reserva do povo Kayapó na região e aí eles foram indenizados. O Governo do estado não tinha recurso pra fazer indenização financeiramente; o que ele fez? Ele chamou os madeireiros e disse que a Gleba Nova Olinda I, onde tá a Terra Indígena Maró, era terra devoluta do Estado que lá não morava ninguém e aí nós vamos negociar com vocês, nós tirar vocês aqui do Sul do Pará e vamos levar vocês aqui pra essa terra e foram pra lá seis, seis empresários. E esse seis 
empresários vinham comunicar o IBAMA que estavam entrando nessa região, eles entraram com esse pedido dia 02 de fevereiro de 2002. Isso é muito gravado na minha cabeça. Eu acabei tendo conhecimento disso e eu comecei a reunir com o povo, comecei a organizar e os cara lá começaram a lotear. Foi a partir daí que despertou a ideia de nós entrar com o pedido de demarcação de terra, nós já morava a muitos anos lá [...] a partir daí que os caras chegaram começaram lotear e aí nós falamos -Não! agora nós temos que entrar com o pedido de demarcação da nossa terra porque senão vamos ficar sem terra. E o governo do estado, em 2006, ele estava destinando as terras, as ADIPs e as permutas e criando assentamento lá na Gleba Nova Olinda, sem fazer consulta prévia, toda irregular. Não existiu nenhuma consulta ali. Quando a gente sabia que os cara estavam reunido. Então isso acabou afetando a gente e começamos a se organizar. A partir daí a gente começou a enfrentar a luta, mas só que foi um pouquinho tarde, porque assim: quando nós fizemos o processo da autodemarcação, em 2007, os cara tinham chegado em 2002; em 2003, o lote deles já estavam todo demarcado e um lote deles estavam dentro tudo da terra indígena. $\mathrm{O}$ Estado mandou o técnico e os madeireiro entraram com apoio logístico, financeiro pros técnicos então... assim que foi feito lá e a partir daí que a gente começou se organizar pra travar a luta (Entrevista com DB, liderança indígena, aldeia de Muratuba/Santarém, maio de 2015).

Percebe-se que a ação do Estado em Nova Olinda, em especial na área onde se localiza a TI Maró, vem favorecendo a formação de grupos empresariais com interesses econômicos na região, visando principalmente a exploração da madeira. Tal fato tem engendrado um grande conflito entre povos indígenas, empresários e Estado, posto a diferença de significado atribuída à natureza por esses agentes sociais. Os indígenas reivindicam o uso coletivo da terra, por meios da demarcação da TI Maró como meio e espaço de vida, empresários e Estado têm demonstrado interesse apenas econômico.

Na Gleba Nova Olinda, segundo Baletti, Sena e Rego (2010), existem 11 planos de exploração madeireira liberados pelo governo do estado do Pará, inclusive dentro de áreas reivindicadas para demarcação de terra indígena Maró. Em áreas conflitantes com a TI Maró atuam quatro madeireiras: Rondobel Indústria e Comércio de Madeira Ltda. com o maior corte de madeira da região, o volume autorizado é de $64.014,24 \mathrm{~m}^{3}$, o que equivale a 3.200 caminhões carregados, comparado às outras empresas que atuam na TI Maró, a Rondobel tem o dobro de corte autorizado. É seguida da PMFS Augusto Braun, que tem autorização para corte de 24.207,72 $\mathrm{m}^{3}$ ou mil caminhões. As empresas Fazenda Curitiba e Lemos Neto e Cia LTDA atuam parcialmente na TI Maró, com volume autorizado de corte fixado $37.417,4$ e $22.200,51 \mathrm{~m}^{3}$, respectivamente (TERRA DE DIREITOS, 2014). 
Conforme entrevista feita como uma liderança indígena em agosto de 2015, foi possível constatar não só a existência de outras madeireiras, como também a flexibilização na execução dos planos de manejo aprovados pela SEMA/PA.

Todo tempo fica mudando o setor madeireiro, um compra um projeto, aí vê a pressão dos indígenas, vende para o outro. A gente sabe que têm muitas empresas terceirizadas. Tem a Mundo Verde e Rondobel que são permuta, mas vem a Alumar, Diniz, L. L. Guerra, Shimith que são terceirizadas. Tem uma série de empresas que compram essas áreas, esses projetos já aprovados pelo governo do Estado e fazem a execução desse projetos que é o corte e o arrasto dessas madeiras. Mas assim, são muitos interesses de muitas empresas. Ficamos sabendo que agora a Andoline comprou de uma empresa madeireira uma área dentro da TI Maró e essa empresa tá operando dentro da TI Maró. Estão fazendo agora o mapeamento, estão fazendo o inventários do projeto de manejo. Isso é uma preocupação pra gente, porque assim, cada ano que passa diferentes empresas pleiteiam o projeto de manejo. A gente não sabe como é que essas empresas trabalham, se são legais ou ilegais e isso o governo, a SEMA, não fiscalizam esses projetos que eles mesmo aprovam (Entrevista com PB, liderança indígena. Santarém, agosto de 2015).

A ênfase na defesa do econômico tem acirrado o conflito na gleba, fato que expõe a situação de inoperância das esferas governamentais na gleba no sentido de garantir a posse da terra e a integridade das famílias que ali residem. A chegada de diversos grupos de grandes produtores na região, sobretudo madeireiros e sojeiros, de fato ameaça a permanência de povos e comunidades tradicionais, assim como intensifica a exploração dos recursos naturais.

Diante do impasse fundiário instalado na Gleba Nova Olinda, os povos indígenas do Rio Maró, visando proteger seu território, deram início a processos de autodemarcação, iniciado em 2005, quando percorreram suas "extremas" e definiram os limites do território. O segundo processo de autodemarcação, ocorrido em 2007, originou-se a partir de articulação do Projeto Saúde Alegria (PSA) e do Conselho Indigenista Tapajós Arapiuns (CITA), do qual Odair José Borari era presidente (FUNAI, 2011).

Em 2007, em parceria com Ministério Público Federal (MPF), a Comissão Pastoral da Terra (CPT) e o Projeto Saúde Alegria (PSA), este último dispunha de tecnologia para georeferênciar os pontos anteriormente identificados pelos Borari e Arapium, como território pertencente a TI Maró, em conjunto com as três aldeias elaboraram o primeiro mapa de delimitação da TI.

Esse primeiro momento marcou a memória dos indígenas, posto que a autodemarcação reforçou um sentimento de pertença a um espaço comum, a partir de narrativas dos mais velhos sobre o uso do espaço e dos recursos há mais 
de uma década. Enquanto campo de experiência e resistência, também legitima o processo de reivindicação política territorial, pois demonstra que os hábitos e os costumes mantidos pelas gerações passadas ainda são praticados pelos jovens (FUNAI, 2011).

Conforme Peixoto, R. e Peixoto, K. (2012), em cenário de cartografias o fato de possuir uma representação cartográfica de si mesmos tem se mostrado fundamental para encaminhar a garantia de direitos territoriais. Uma projeção cartográfica de uso da terra para os indígenas é constituída de uma série de elementos materiais e simbólicos que obedece critérios de uso sociais e ambientais do espaço vivido. Assim, o território se constitui por um conjunto de ações definidas em relação ao objetivo de um ou uns sujeitos. Não se tratando de um espaço, mas de um espaço construído pelos sujeitos, desta forma, falar de território é falar de identidade e de recursos, onde os seus limites geográficos se dão pelas relações cotidianas.

\section{AMEAÇAS E CRIMINALIZAÇÃO DE LIDERANÇAS INDÍGENAS}

As pesquisas e os registros sobre os conflitos na Gleba Nova Olinda têm apontado a existência de diferentes estratégias utilizadas pelos agentes sociais para fazer frente aos conflitos. Com o vazio institucional característico da Amazônia, o despreparo dos agentes do Estado, acrescentado a morosidade da demarcação da TI e do ordenamento fundiário da Gleba Nova Olinda, associado a condição de pobreza das comunidades tradicionais locais, deixam os agentes privados mais à vontade para operar seus interesses e violações naquele território (ASSIS, 2010; SAUER; MARÉS, 2013). A cooptação, a violência e a criminalização de lideranças indígenas têm sido utilizadas pelos madeireiros, como mecanismos para apropriação de terras públicas, como apontado no relatório do IBAMA, elaborado em 2007:

táticas de cooptação das comunidades aliadas da Rondobel [...] sustenta suas manobras com promessas de geração de emprego, oferta de geradores de luz, televisores, escolas estradas, transporte para o deslocamento dos trabalhadores, combustíveis para utilização pessoal ou comunitária, georreferenciamento dos lotes dos comunitários regularizados e titulados pelo ITERPA, que vem sendo custeado pelos empresários, o que aumenta da dependência dos primeiros, em relação aos segundos (IBAMA, 2007).

Cooptar tem a função ideológica de trazer para si o que se apresenta como adversário. Neste caso, a ineficiente ação do Estado, no que se refere às necessidades sociais dos povos e comunidades tradicionais na Gleba Nova 
Olinda I, tem sido uma forte aliada no processo de cooptação das lideranças das comunidades localizadas ao entorno da TI Maró. Este fato tem contribuído em vários aspectos com os interesses das madeireiras na área, principalmente em relação aos indígenas, uma vez que, as comunidades cooptadas se mostram contrárias à demarcação do território indígena.

As práticas de violência física também têm sido outra estratégia dos empresários no conflito que envolve indígenas e madeireiros na área. O caso mais emblemático é o que envolve a liderança indígena $\mathrm{DB}$, vítima de várias ameaças e atentados, tendo inclusive sido sequestrado em junho de 2007.

Foi dia 07.06.2007, aí eu fui naquele banco, no Bradesco, não no Itaú, ao sair do Itaú, eu pego a moto [...]. Quando vai chegando na Borges Leal, aí uma L-200 assim, fecha a gente na rua o cara abre a porta o cara botou uma 38 em cima de mim, "entra pra cá e não fala nada", aí o outro saiu do lado dali, da porta do carro e roda por lá. Aí eu fiquei ali tentando dizer que não queria e o outro que rodou o carro ali já foi me metendo a pistola e já me empurrando, entrei a pulso né. No que eu entrei no carro, os cara arrancaram minha camisa e amarraram no meu rosto e ai eles saíram. Quando uns dois minutos depois, eu meto a mão e puxo, os cara iam, um com uma 38 desse lado e o outro com a pistola assim, lá não podia fala nada. Aí eu meto a mão e puxo e vejo que nós ia saindo de Santarém em direção a Alter do Chão [...] eles pegaram e pararam o carro lá e me levaram a 60 metros da pista pra dentro do mato, me amarraram no pé de duas árvores, isso aconteceu umas dez da manhã quando a polícia conseguiu me resgatar tava umas 19:30 [...] olha eu fui muito batido, muito batido mesmo [...] Quando deu por volta das quatro e meia mais ou menos eu consegui arrancar o cipó que tava amarrado desse lado aqui. Mas aí eu já tava sem força o braço todo inchado porque tava amarrado aqui e aqui e aí eu consegui desmanchar daqui arrebentar o cipó e consegui pega o celular. E tinha um cidadão, eram quatro, três foram embora e um ficou lá, que vinha lá encostava a arma lá em mim e me confessava, perguntava se eu ainda ia impedir o progresso que tava chegando em Santarém, o progresso tava chegando na Gleba Nova Olinda se eu ainda ia impedir, então tava claro quem que era os cara e eu logicamente humilhado pelos cara, eu falava não, não vou mais impedir tal, vou ficar na minha casa humilha, humilhado. Bom e aí ... (questão de sobrevivência não tinha né?) não tinha outro jeito [...] depois que tava lá no serviço não aguentei, não aguentei comecei a dá aquele enjoo no estômago e comecei a provocar sangue, mijei sangue. Ai pego e desço pra Santarém, venho pro hospital de novo e o povo continuou lá (mas devido) devido muita "espancação" (Informação verbal) ${ }^{5}$.

\footnotetext{
Informação verbal obtida por meio de entrevista com DB, na Aldeia de Muratuba/Santarém, em maio de 2015.
} 
Este fato que levou a sua inclusão no Programa de Proteção aos Defensores de Direitos Humanos do Estado do Pará (PPDDH) ${ }^{6}$, onde recebe proteção policial, no mesmo ano a liderança indígena ganhou o prêmio José Carlos Castro de Direitos Humanos, oferecido pela Secional da Ordem dos Advogados do Brasil (OAB) do Pará. O prêmio foi em reconhecimento da luta política da liderança pela demarcação da TI Maró, assim como pelas denúncias de exploração ilegal de madeira na área da Gleba Nova Olinda. A escolha do cacique para receber o prêmio foi de uma comissão julgadora composta pela presidente da entidade, dirigentes da Comissão de Direitos Humanos da OABPA e conselheiros, além de representantes da Comissão Pastoral da Terra e do Ministério Público Federal.

Em um depoimento extravasante, DB verbaliza todo seu sentimento em relação à mudança de vida desde que iniciou a luta junto ao movimento indígena pela demarcação da TI Maró, fala dos reflexos disso no seu cotidiano e de sua família, apontando os danos morais e psicológicos que sofrem.

Hoje eu sou processado, hoje eu respondo processo, hoje eu sou ameaçado e eu vivo preso, parente, isso que eu gostaria de falar pra vocês, eu vivo preso pelo governo do estado. Eu fui preso desde 2007 até hoje, porque a partir do momento que eu ponho um pé em Santarém eu tenho dois policiais do meu lado. Então isso é prisão porque eu não tenho a minha liberdade, não tenho a minha liberdade. Então, isso pra mim é um presidio porque acabou com minha liberdade. Se eu tenho que ir pra uma reunião, eu tenho que falar para os policiais que me acompanham: "olha, eu vou pra uma reunião tal, tal, tal, assunto tal”, porque se eu não esclarecer não posso participar daquela reunião. Cês entenderam a luta do povo indígena do Borari e Arapium da TI Maró Só pra vocês terem essa noção, parente. É uma luta suada, incansável, desgastante. Isso nós sofremos, você pense e analise o dano psicológico, o dano psicológico que eu enquanto cacique sofro. Que a minha mãe, que não tem aqui, parente, mãe nenhuma que aceita, que aceita a perseguição com seu filho. Não existe mãe nenhuma que aceita. A minha mãe hoje tá sofrendo, a minha mãe tá doente, a minha mãe não tá aqui, porque eu e meus irmão... Então parente, a nossa luta indígena é uma luta incansável, eu hoje, eu posso tá sorrido pra você, mas o meu psicológico, ele tá sofrendo. Porque o meu psicológico e o meu corpo não tem liberdade. Desde 2007 até hoje, nunca mais eu me

6 A política nacional de proteção aos defensores dos direitos humanos foi instituída pelo Decreto Presidencial no 6.044, de 12 de fevereiro de 2007. O programa foi criado em 2004 e tem como objetivo a adoção e articulação de medidas que possibilitem garantir a proteção de pessoas que estejam em situação de risco ou ameaça em decorrência de sua atuação na promoção ou defesa dos direitos humanos. Para a inclusão do defensor dos direitos humanos no Programa de Proteção são observados os seguintes requisitos: solicitação de avaliação, comprovação de que o interessado atue na defesa ou na promoção dos direitos humanos; identificação do nexo de causalidade entre a violação ou ameaça e atividade de defensor dos direitos humanos; anuência e adesão às suas normas. 
diverti em uma festa com meus parentes, porque não tenho essa liberdade, porque a proteção que me faz a segurança não deixa nem eu participar de festa. Em Santarém eu só posso tá até as $19 \mathrm{~h}$, após as $19 \mathrm{~h}$ eu não posso ta em praça públicas, eu não posso andar de ônibus, eu não posso tá em lugares públicos, eu tenho que tá escondido. O que que é isso? É negação do meu direito. A minha privacidade acabou. [...].

Ressalte-se que o caos fundiário verificado na região da referida gleba se deve menos ao reconhecimento das comunidades indígenas de Cachoeira do Maró, São José III e Novo Lugar, do que à atuação predatória de grupos madeireiros, interessados no apossamento das terras das referidas comunidades. Ao se valerem da difamação, ameaças, criminalização de lideranças, torturas e até mesmo tentativas de assassinato, tais grupos adotam estratégias seculares e nefastas de organização fundiária.

A criminalização do movimento indígena que luta pela demarcação da TI Maró, principalmente de seus líderes, tem sido um recurso muito utilizado pelas empresas como forma de engessar "o crescimento de uma força política com capacidade de questionar e colocar em 'cheque' as convenções (leis normativas legais e administrativas) e posicionamentos políticos oficiais sobre a propriedade privada da terra” (COSTA, 2012, p. 171).

Além das ameaças sofridas, foram abertas contra as lideranças do movimento indígena ações judiciais e penais, sob tais acusações: ameaça, cárcere privado, incêndio em embarcações, atentado contra a segurança de transporte marítimo, quadrilha armada, desobediência, exercício arbitrário das próprias razões. Além dessas acusações, o Inquérito Policial nº 302/2009.000187-5PC/PA que culminou com a Ação Penal, imputou ao cacique Dadá Borari o crime de falsidade ideológica. Ainda que o Ministério Público Estadual (MPE) não tenha oferecido esta última denúncia à justiça, o fato demonstra a pressão que os indígenas sofrem diante da luta pelo território, pela identidade, pelo particular modo de vida que não coaduna com os interesses econômicos existentes sob o território.

Simultaneamente, ao acima apresentado, os indígenas enfrentam todo tipo de ataque, de outro importante aliado no processo de marginalização do movimento indígena, a mídia. Para Girardi Jr (2007), o campo da comunicação tem destacado a importância da mídia no estabelecimento de agendas temáticas, sendo que esta seria de fato uma das suas funções fundamentais, onde o poder dos meios de comunicação de massa não consistira propriamente, em nos dizer 
o que pensar, mas em que pensar, isto é, na sua capacidade de dar visibilidade a um assunto e fixar uma agenda temática (política, ideológica, cultural, econômica, social e ambiental).

O papel midiático na questão indígena na Gleba Nova Olinda tem fortalecido um discurso preconceituoso, contra a luta indígena no baixo Tapajós. A exemplo da reportagem do jornalista Inácio Régis publicada no jornal O Estado do Tapajós, de 30 outubro a 05 de novembro de 2009, com a seguinte chamada "Greenpeace 'fabrica' índios". A reportagem trazia passagem como: "nunca existiu índio na Gleba Nova Olinda. As ONG é que ensinam eles. Eles só se vestem e se pintam como índios quando vão falar com pessoas do governo, para poder enganar [...]. Também, reveste-se de falsidade ideológica, o fato de O J intitular-se cacique de uma etnia extinta [...]".

Girardi Jr (2007), apoiado em Bourdieu, diz que uma teoria da comunicação só pode existir integrada a uma teoria da ação. Neste sentido, podemos inferir que o posicionamento da mídia desfavorável à demarcação da TI Maró, tem por objetivo fortalecer os interesses empresarias madeireiros na Gleba. A preocupação exacerbada com audiência e o controle sobre as condições de percepção dos produtos culturais dão origem a uma multiplicidade de formas de "censura invisível", de formas específicas de violência simbólica (GIRARDI JR., 2007, p. 139).

As situações de ameaças foram também vivenciadas e registradas pela equipe da FUNAI no Relatório Circunstanciado de Identificação e Delimitação dos Limites da TI Maró (RECID), no ano de 2011.

Reconhecida a importância do igarapé, o GT organizou uma ida junto com os indígenas para conhecimento da área, que teve que ser abortada, pois a equipe foi impedida pelos moradores da Cachoeira do Aruã de chegar até uma das estradas que da acesso ao igarapé. Os indígenas foram pela floresta, com medo de represálias de outras comunidades, enquanto a equipe foi pela estrada para também verificar a condição da cabeceira do Igarapé do Arraia e a retirada de madeira pela estrada que corta o território ao meio. Depois deste incidente, os pesquisadores não se sentiram seguros para percorrer mais extremas/limite [...] seguiram recomendações que confirmou a possibilidade de coleta de informações junto a base de dados cartográficos de instituições governamentais (FUNAI, 2011, p. 75).

A situação apresentada tem esmorecido as práticas tradicionais desenvolvidas pelos indígenas de caça, pesca e tratamento medicinal, devido ao impedimento da circulação dos Borari e Arapium por seu território, os indígenas 
não podem mais frequentar áreas que ocupam há mais de 50 anos, como cabeceira de igarapés ${ }^{7}$, como Cachimbo, Arraia, Raposa e parte da mata.

\subsection{UM JULGAMENTO E UMA SENTENÇA - A SENTENÇA EM JULGAMENTO}

Diante do acirramento do conflito, o Ministério Público Federal (MPF) propôs a Ação Civil Pública (ACP), protocolada em março de 2010, que tramitou na $2^{\mathrm{a}}$ Vara da Justiça Federal de Santarém sob o processo n 2010.39.02.0002490 . Nesta o MPF cobrava da FUNAI o Relatório Circunstanciado de Identificação e Delimitação dos Limites da Terra (RECID) Indígena Maró, com os estudos de natureza etno-histórica, antropológica e ambiental, necessários à identificação e à delimitação da TI.

O Grupo de Trabalho (GT) para realização do estudo na TI havia sido instituído em julho de 2008, por meio da Portaria n⿳⺈ 775, desde então o Processo Administrativo (PA) no 1.23.002.000792/2005-65 encontrava-se paralisado, sem justificativa razoável, não tendo obedecido os prazos estabelecidos pela legislação. Assim, a ACP visava o imediato prosseguimento do processo administrativo de demarcação da Terra Indígena dos Borari e dos Arapium.

Contrária à ACP do MPF e ao PA da FUNAI pela viabilização dos estudos e respectiva demarcação da TI, se tem uma ACP “movida” por 7 (sete) ${ }^{8}$ associações comunitárias ribeirinhas cooptadas pelos empresários, que foram usadas para mover o processo desfavorável ao reconhecimento de terra indígena. A ação das associações se iniciou como Ação de Anulação de Processo Administrativo c/c Inexistência de Etnia e Posse Indígena, mas, "por razões processuais juntou-se à ACP do MPF de Santarém" (MARQUES, 2016). O processo foi protocolado em 18 de junho de 2010 e tramitou na Justiça Federal de Santarém sob o nํ209180.2010.4.013902.

\footnotetext{
Essas áreas são imprescindíveis para os Borari e os Arapium, além de serem espaços que asseguram a segurança alimentar dos indígenas, também são espaços de morada dos encantados, onde estão localizados os campos de natureza, lugares considerados sagrados e que não sofrem modificação humana (FUNAI, 2011).

8 (1) Associação Intercomunitária de Trabalhadores Agroextrativistas das Comunidades de Prainha e Vista Alegre do Rio Maró (AINORMA), (2) Associação Intercomunitária de Moradores e Trabalhadores rurais e Agroextrativistas das Comunidades de São Luiz (AMAGLO), (3) São Francisco, São Raimundo e N. Paraiso, (4) Associação dos Moradores das Comunidades Fé em Deus Agroflorestal e Extrativista da Gleba nova Olinda (ASCOME), (5) Associação dos Moradores da Comunidade Sempre Serve Agroflorestal e Extrativista (ASSERVE) (6) Associação dos Moradores da Comunidade Repartimento Agroflorestal e Extrativista (AMREP) e (7) Associação dos Moradores da Comunidade dos Parentes, Agroflorestal e Extrativista (AMOVIT).
} 
O Relatório Circunstanciado de Identificação e Delimitação da Terra Indígena Maró, publicado em outubro de 2011, a partir dos estudos ambiental e antropológico, contempla no mapa de delimitação da terra indígena a área que encontra-se em litígio entre indígenas e madeireiros. Os estudos mostram a importância e a necessidade dá área para reprodução sociocultural dos Borari e Arapium, os estudos também apontam que não existe sobreposição da TI Maró com as comunidades ao entorno, em particular com as "autoras" da ação judicial.

Segundo Bourdieu (1983), a estrutura da relação de produção linguística depende da relação de força simbólica entre os dois locutores, isto é, da importância de seu capital de autoridade, desta forma a língua não é apenas um instrumento de comunicação, mas também de poder. Ao julgar as ACP e proferindo a sentença em novembro de 2014, o Juiz federal de primeira instância Airton Portela, fazendo uso poder simbólico a ele instituído pelo cargo ocupado no Estado, julgou e sentenciou a não existência dos Borari e dos Arapium.

Fundamentando-se no senso comum, na idealização e estereótipos da figura do índio como um índio genérico sem identidade étnica específica, numa mera reprodução da imagem criada pelos colonizadores, o juiz federal José Airton de Aguiar Portela reproduz na sentença toda a representação e preconceito étnico contra os indígenas.

$\mathrm{Na}$ contestação da sentença feita pelo MPF é evidenciada a ação de cooptação das associações comunitárias (autoras da ação judicial) pelos madeireiros, quando se identifica que as áreas das comunidades não sobrepõem com a TI Maró, mas somente com as terras exploradas pelos madeireiros: "evidente que se trata de legitimidade extraordinária ilegal: as comunidades ribeirinhas pedindo em nome das madeireiras. [...] não há qualquer comprovação de que a TI Maró se sobrepõe às áreas ocupadas pelas comunidades ribeirinhas que compõem as Associações, o que impossibilita qualquer decisão do Juízo em face da ausência das condições da ação, que, por seu turno, importa em extinção do processo sem julgamento do mérito (BRASIL, Ministério Público Federal 2014, p. 10).

Para além das questões de sobreposição a sentença vai mais longe e declarou que os indígenas não atendiam os "requisitos indispensáveis", como "origem e ascendência pré-colombiana e "ser identificado como pertencente a um grupo étnico cujas características culturais o distinguem da sociedade nacional"; declarando ainda "inválidos todos atos praticados no processo administrativo 08620.000294/10 (TI Rio Maró) da FUNAI. Seguiu determinando que "a União e a FUNAI se abstenham de praticar quaisquer atos previstos ou não pelo 
Decreto n 1.775/1996", ato que dispõe sobre os procedimentos de demarcação da terra indígena.

Ao julgar improcedente os estudos de práticas e costumes apresentados pelo RECID ${ }^{9}$, elaborado pela FUNAI, o juiz afirma que, em lugar de comprovar a existência de índios no Baixo-Tapajós e Arapiuns, antes revelam tratarem-se de populações tradicionais ribeirinhas (São José III, Novo Lugar e Cachoeira do Maró) e que em nada se distinguem das onze comunidades restantes (de um total de 14) que formam a Gleba Nova Olinda, assim, como também nada há que se divisar como elemento diferenciador das demais populações rurais amazônicas (BRASIL, 2014, p. 08).

Assim, a sentença proferida pelo juiz pode ser concebida com um dispositivo jurídico emergencial que garantisse a exploração madeireira na área demarcada para integrar o território Maró, uma vez que estudos tecnicamente competentes e legítimos, no caso do RECID, integraram a área sobreposta como pertencente a TI Maró, o que configura um importante avanço para demarcação da TI.

O conteúdo da sentença gerou protestos no movimento indígena, que, em 9 de dezembro de 2014, realizou uma grande manifestação na cidade de Santarém, contestando a sentença autocrática e racista do referido juiz. $\mathrm{Na}$ ocasião ocuparam o prédio da Justiça Federal por dois dias, seguindo depois para sede do MPF, para reunião em que estiveram: o procurador do MPF, o procurador da FUNAI, a advogada da Terra de Direitos, a CPT, estudantes e professores de Antropologia da UFOPA, representantes do CITA e lideranças indígenas. $\mathrm{Na}$ ocasião, foi explicado que o próximo passo é tentar reverter a sentença por meio do recurso de apelação.

Marcada pelo desrespeito e racismo contra os Borari e Arapium, pela falta de ética em julgar quesitos que não cabe à justiça de primeiro grau, coadunada com a tentativa de negação de um trabalho antropológico, que requer uma formação especifica dentro da ciência sociológica, a sentença foi suspensa pela fragilidade de conteúdo e por ferir alguns princípios do código de processo civil e da Constituição, porém enquanto dispositivo de urgência para garantir a exploração de recurso madeireiro, cumpriu com seu papel.

Como estratégia da resistência, destaca-se a Convenção 169 (1989) da Organização Internacional do Trabalho (OIT), a qual é o principal tratado internacional sobre direitos de povos indígenas e tribais, considerado o instrumento jurídico mais avançado no tratamento das relações entre os Estados e povos

\footnotetext{
O RECID apresenta manifestações culturais como: batismo de casa, puxiruns, tarubá, puxar barriga, chibé, cultuar o encantado, respeitar locais sagrados, como a mata e cachoeiras, a prática da pesca, o uso de tarrafa, entre outros.
} 
indígenas em todo o mundo. No Brasil foi promulgada em 19 de abril de 2004, por meio do Decreto $\mathrm{n}^{\circ}$ 5.5051, e ingressou no ordenamento jurídico brasileiro fazendo dele parte como força vinculante, seja com status supralegal ou com força de Emenda à Constituição (MINISTÉRIO PÚBLICO FEDERAL, 2014).

Dentro dos direitos propostos pela convenção 169 aos povos indígenas, seu artigo primeiro destaca que "a consciência de sua identidade indígena ou tribal deverá ser considerada como critério fundamental para determinar os grupos aos que se aplicam as disposições da presente Convenção".

Conforme o Ministério Público Federal (2014), o critério do autorreconhecimento não merece reparos, na definição de uma identidade étnica, e é fundamental levar em consideração as percepções dos próprios sujeitos que estão sendo identificados, de forma a evitar preconceitos e pré-noções, diante de uma cultura diferenciada. Garantir o autorreconhecimento no caso dos povos indígenas é respeitar o princípio da dignidade da pessoa humana, que o próprio sujeito de direto tem de si (MINISTÉRIO PÚBLICO FEDERAL, 2014), tudo que o juiz não fez.

Conforme Almeida (2008), a efetivação dos dispositivos constitucionais e infraconstitucionais se deparam com imensos obstáculos que tanto são forjados mecanicamente nos aparatos burocráticos administrativos do Estado, quanto são resultantes de estratégias engendradas, seja por interesses que historicamente monopolizaram a terra, seja por interesse de "novos grupos empresariais" interessados na terra e demais recursos naturais.

A situação da TI Maró continua não resolvida, e o processo de reconhecimento da TI ainda está em andamento e na fase judicial de recurso em trâmite no Poder Judiciário. Longe de uma solução imediata, o longo percurso processual judiciário possibilita que os recursos naturais continuem sendo explorados na região, colocando em risco a permanência e sobrevivência dos indígenas.

\section{CONSIDERAÇÕES FINAIS}

O conflito fundiário que envolve a Gleba Nova Olinda, principalmente a TI Maró, desvela elementos intrínsecos à complexa realidade histórica, econômica, social, política e cultural de uma sociedade que tem sido moldada de forma a atender as necessidades de mercado. Para Polanyi (2000, p. 77), a evolução do padrão de mercado se torna vital para a existência da sociedade. Desta forma, em vez de a economia estar imbuída nas relações sociais, são as relações sociais que estão imbuídas no sistema econômico. Assim, a sociedade tem que ser adaptada 
de modo a permitir que o sistema econômico vigente funcione conforme suas leis - uma economia de mercado só pode funcionar numa sociedade de mercado.

A apropriação da natureza pela sociedade de mercado tem aprofundado conflitos fundiários, onde os agentes sociais que têm modo de vida diretamente ligado à natureza: terra, água, ar, floresta, são alvos de constantes ameaças, posto que o bem comum resguarda riquezas naturais que muito interessam a grandes grupos empresariais, que visam ampliar a acumulação de seu capital.

O espaço territorial em seus diversos níveis é moldado e condicionado sob a lógica capitalista, e a Amazônia, neste início do século XXI, tem sido de forma incisiva um dos maiores, se não o maior exemplo da conversão econômica da natureza ao processo de acumulação do capital. Conforme Costa (2012), o aquecimento atual do mercado de terras convergem para o entendimento de que estão em execução estratégias governamentais e empresarias que propõe e articulam ações cujo objetivo é a liberação de terras tradicionalmente ocupadas para a compra e venda no mercado.

\section{REFERÊNCIAS}

ALMEIDA, A. W. B. de. Terras tradicionalmente ocupadas: terra de quilombos, terras indígenas, "babaçuais livre", "castanhais do povo", faxinais e fundos de pasto. 2. ed. Manaus: UFAM, 2008.

ARENZ, K; FIGUEIREDO, R; PEIXOTO, K. O movimento indígena no Baixo Tapajós: etnogênese, território, Estado e conflito. Novos Cadernos NAEA. Belém, v. 15, n. 2, p. 279-313, dez 2012.

ASSIS, W. F. T. Conflitos territoriais e disputas cartográficas: tramas sociopolíticas no ordenamento territorial do Oeste do Pará. In: ACSELRAD, H. Cartografia social e dinâmicas territoriais. Rio de Janeiro: UFRJ, Instituto de Planejamento Urbano e Regional, 2010.

BALETTI, B.; SENA, A.; REGO, G. Em defesa da Amazônia moradores enfrentam madeireiros e o governo em batalhas locais. Janeiro de 2010. Disponível em: <http://www.ircamericas.org>. Acesso em: 14 dez. 2014.

BOURDIEU, P. Questões de Sociologia. Rio de Janeiro: Marco Zero, 1983.

BRASIL. Justiça Federal de Primeiro Grau no Pará: Segunda Vara da Subseção de Santarém. Sentença dos Processos: 2010.39.02.000249-0 e 209180.2010.4.01.3902 (ações civis públicas). $1^{\circ}$ Autor: Ministério Público Federal. $2^{\circ}$ Autor: Associação Intercomunitária de Trabalhadores Agroextrativistas de 
Prainha e Vista Alegre do Rio Maró e outros. Réus: Fundação Nacional do Índio e União. Juiz: José Airton de Aguiar Portela. Santarém, 26 de novembro de 2014. Disponível em: <http://www.prpa.mpf.mp.br/news/2015/arquivos/ Sentenca_TI_Maro.pdf>.Acesso em: 27 jul. 2016.

. Presidência da República. Lei n. 11.284, de 2 de março de 2006. Dispõe sobre a gestão de florestas públicas para a produção sustentável; institui, na estrutura do Ministério do Meio Ambiente, o Serviço Florestal Brasileiro - SFB; cria o Fundo Nacional de Desenvolvimento Florestal - FNDF; altera as Leis $\mathrm{n}$ 온 10.683 , de 28 de maio de 2003, 5.868, de 12 de dezembro de 1972, 9.605, de 12 de fevereiro de 1998, 4.771, de 15 de setembro de 1965, 6.938, de 31 de agosto de 1981, e 6.015, de 31 de dezembro de 1973; e dá outras providências. Disponível em: $\quad$ <http://www.mma.gov.br/port/conama/legiabre.cfm?codlegi=485>. Acesso em: 20 jan. 2016.

CADERNO Nova Cartografia e Mapeamento Sociais: povos e comunidades tradicionais e suas práticas sociais de preservação dos recursos naturais na Amazônia. Manaus, 2014

CASTRO, E.; MONTEIRO, M.; CASTRO, C. P. Atores e relações sociais em novas fronteiras na Amazônia. Brasília, Banco Mundial (Relatório de Pesquisa), 2002.

COSTA, S. M. G. da. Grãos na floresta: estratégia expansionista do agronegócio na Amazônia. 2012. Tese (Doutorado em Desenvolvimento Sustentável do Trópico Úmido) - Núcleo de Altos Estudos Amazônicos, Universidade Federal do Pará, Belém, 2012.

FOUCAULT, M. Microfísica do poder. Organização e tradução: Roberto Marchado. Rio de janeiro: Edição Graal, 1979.

FUNAI. Relatório Circunstanciado de Identificação e Delimitação dos Limites da Terra Indígena "Maró" (Rio Maró). São Gabriel da Cachoeira, AM: FUNAI, 2011.

GIRARDI JR, L. Pierre Bourdieu. Questões de sociologia e comunicação. São Paulo: Annablume; Fapesp, 2007.

GOVERNO DO ESTADO DO PARÁ. Procuradoria Geral do Estado, 2014. Processo no 2091-80.2010.4.01.3902.

IBAMA. Relatório Técnico de Vistoria na Gleba Nova Olinda, 2007. 
LOUREIRO, F. V. A Amazônia no século XXI: novas formas de desenvolvimento. São Paulo: Empório do Livro, 2009.

MARQUES, D. B. G. Direitos Humanos e Autorreconhecimento da Demarcação da Terra Indígena Maró, Santarém-PA. Dissertação (Mestrado em Direito) - Instituto de Ciências Jurídicas, Universidade Federal do Pará, Belém, 2016.

MESQUITA, A. B. Conflitos Territoriais na Amazônia na "Era do Capital", 2011.

MILANEZ, F. Sentença da Justiça Federal acirra conflitos em Santarém. Carta Capital. 12 dez. 2014. Disponível em: <http://www.cartacapital.com.br/blogs/ blog-do-milanez/sentenca-da-justica-federal-exalta-racismo-a-indigenas-eacirra-conflitos-em-santarem-6596.html>. Acesso em: 20 dez. 2014.

MINISTÉRIO PÚBLICO FEDERAL. Recurso: contra a sentença judicial da Terra Indígena Maró, 2014.

Ação Civil Pública. 2010.

PEIXOTO, R.; PEIXOTO, K. A luta territorial dos indígenas da terra Maró. Somanlu, Manaus, v. 12, n.2, p. 175-197, jul/dez. 2012.

POLANYI, K. A grande transformação: as origens a nossa época. Tradução: Fanny Wrobel. 2. ed. Rio de Janeiro: Campus, 2000.

SAUER S.; MARÉS, C. F. (Coord.). Casos emblemáticos e experiências de mediação: análise para uma cultura institucional de soluções alternativas de conflitos fundiários rurais. (Diálogos sobre a Justiça). Brasília: Ministério da Justiça, Secretaria de Reforma do Judiciário, 2013. 155 p.

\section{TERRASDEDIREITOS.Quemganhacoma“inexistência”da'TerraIndígena}

Maró? Disponível em: <http://terradedireitos.org.br/2014/12/17/quemganha-com-a-inexistencia-da-terra-indigena-maro/>. Acesso em: 04 fev. 2014. 
